\title{
On the nature of collocations and ways of teaching them in foreign language classes
}

\author{
TÜNDE NAGY*
}

Department of Human Sciences, Sapientia Hungarian University of Transylvania, Miercurea-Ciuc, Romania

\section{THEMATIC ARTICLE}

Published online: May 12, 2020

(C) The Author(s) 2020

\begin{abstract}
When it comes to teaching vocabulary in foreign language classes words are often taught in isolation, without regard to the context in which they appear. The paper draws attention to the importance of teaching words in context so that the meaning of a word often results from the meaning of a larger construction it is part of. After presenting the morpho-syntactic and semantic characteristics of collocations, and the difficulties language learners face in acquiring them, the paper presents a few ideas on how to teach collocations, giving examples of activities and exercises that can facilitate the learning process. The focus has been laid on activities that can complement the lessons in class, can be applicable at different levels and also require relatively little preparation from the part of the teacher. In addition, an important aspect has been to choose activities that language learning have fun doing (that include creativity, problem solving, humor, real life examples, own experiences, etc.) and that integrate the necessary language learning skills (speaking, listening, reading, and writing). Without the intention of being exhaustive, the paper concentrates on those activities and tasks that present collocations in their entirety, as constructions, assuming that these are the most useful for students. While the ideas presented are generally applicable in foreign language classes, the present paper has been written with native Hungarian speakers in mind.
\end{abstract}

\section{KEYWORDS}

collocations, constructions, morpho-syntactic and semantic properties, foreign language acquisition, exercises and activities

\footnotetext{
* Corresponding author. E-mail: nagytunde@uni.sapientia.ro
} 


\section{INTRODUCTION}

With the appearance of the lexical approach in the early 1990s the importance of teaching lexical phrases as chunks was realized and so was the necessity to teach collocations in class. This has however never been an easy endeavor as it involves making language learners acknowledge words in context instead of individual words. It is a well-known fact that students often have difficulty acquiring and using collocations correctly (they often lack receptive and productive collocational competence), due to several reasons that on the one hand result from the high number and also complex nature of collocations (there are different types of collocations with varying degree of transparency and substitutability of the component elements) on the other hand to other factors that may hinder the acquisition process (possible negative transfer from L1 (or L2), unawareness of the existence of collocations, the tendency to learn individual words instead of chunks, as well as the salience and frequency of a particular construction, etc.). After giving an insight into the morpho-syntactic and semantic properties of collocations and pointing out in more detail the causes for the relative slow uptake of collocations by language learners the paper discusses questions related to the teaching methodology of collocations and gives a few practical ideas on how to teach collocations to different levels.

\section{COLLOCATIONS AS MULTI-WORD CONSTRUCTIONS}

Despite the fact that the analysis of collocations has been met with great interest lately, no exact definition of these linguistic constructions can be found as yet. The term itself comes from the Latin term collocare (com-together + locare (locus-place) - meaning place together, referring to words that are often used together. Among the first linguists to introduce this term are H.E Palmer in his (1933, p. 13) Interim report on Collocations, defining collocations as "the succession of two or more words that must be learned together as an integral whole and must not piece together from its component parts" (title page) (as cited in Williams \& Millon, 2012). Providing a detailed list of thousands of collocations, Palmer notes that the number of collocations exceeds the number of single words and that they pose different problems for comprehension and production (as cited in Stubbs 2009, p. 17). Another influential work on the study of collocations is that of Firth (1957) who defines collocations as "the company a word keeps" (p.11) as well as "actual words in habitual company" (p.14). In his attempt to define lexical meaning at syntagmatic level, Firth (1957, p. 11) talks about "meaning by collocation", which according to him reflects the ability of a specific word to collocate with other words.

Later approaches to collocations pick up on the ideas expressed both by Palmer (1933) and Firth (1957); among the numerous definitions we can mention that of Leech (1974, p. 20), according to whom collocative meaning is "the association a word requires on account of the meaning of words which tend to occur in its environment", or that of Hoey $(1991$, p. 7) who sees collocations as "the relationship a lexical item has with other items that appear with greater than random possibility in (its) textual context". While there are many collocations that contain two co-occurring lexical items (e.g., rancid butter, heavy rain), a collocation can consist of several items, which made Sinclair (1991, p. 170) define collocations as "the co-occurrence of two or more words within a short space of each other in a text."

It is quite difficult to give a precise definition of collocations due to their heterogeneity and complex nature. According to Schmid (2003, p. 238) the reason why linguists find it difficult to define collocations is that collocations represent cases of gradience, ranging from more prototypical (recurrent 
binary constructions, such as pay attention (verb phrase)slight problem (adjective + noun phrase), etc. to less typical constructions (that include prepositions and other function words, such as run out of something (verb phrase plus prepositional phrase). Collocations can be regarded as halfway entrenched word combinations (Schmid 2003, p. 235) whose constituent elements are often not interchangeable and which may or may not allow for additional elements to be inserted, consider large/big/huge problem (all possible) pay(close) attention but by and large, safe and sound, peace and quiet, etc. Schmid (2003, p. 244) lists as criteria for the definition of collocations the requirement adjacency (words should be adjacent within a certain span), combined recurrence (collocations are recurrent constructions) and mutual expectancy or probability (collocations are more predictable the more frequent they are).

In line with the framework of cognitive grammar, and especially construction grammar (Goldberg, 1995, 2006) this paper defines collocations as constructions, pairings of form with meaning, with independent semantic and syntactic properties. Constructions can be considered patterns with a schematic syntactic configuration (e.g., noun + verb, verb + noun, adjective + noun, adverb + adjective, verb + adverb in the case of lexical collocations) and with a meaning that is often more than the sum of the meaning of the component parts. This also means that constructions are to a certain degree unpredictable (so that the meaning of a construction is not always predictable from its component parts or from other constructions) and appear in the language with sufficient frequency (Goldberg, 1995, 2006).

\section{THE MORPHO-SYNTACTIC AND SEMANTIC PROPERTIES OF COLLOCATIONS}

Regarding their morpho-syntactic properties, collocations pertain to two major groups, lexical and grammatical collocations, depending on the part of speech the constituent elements belong to (Benson, Benson and Ilson, 1986). The first category contains a variety of combinations, such as verb + noun, e.g., make a promise, adjective + noun, e.g., strong tea, noun + verb, e.g., plane takes off, noun + noun, e.g., child care, adverb + adjective, e.g., hopelessly devoted, verb + adverb, e.g., argue heatedly. Different from lexical collocations, grammatical collocations often contain a noun, a verb or an adjective followed by preposition, or a grammatical construction, like a to-infinitive construction or a that clause, for example, at night, extend to, be interested in, be inclined to do something, etc. While constructions are usually made up of two words in close proximity, this is not always the case, so that collocations can also contain additional elements, consider the adverb + verb + article + adjective + noun + preposition + noun construction $=$ seriously affect the political situation in Bosnia (Hill, 2000, p. 49) or may not be directly adjacent, having words intervening between the collocates (e.g., provide some of the information (non-adjacent collocation) vs. provide information (adjacent) (Vilkaite, 2016, p. 2) or take considerable amount of time to do something vs. take time to do something. Non-adjacent constructions occur equally, if not even more frequent than adjacent constructions and according to a study based on an eye-tracking experiment of language processing they can show similar processing advantages (are processed equally fast) (Vilkaite, 2016, p. 9).

From a semantic point of view, collocations are made up of two parts: the base that bears most of the meaning of the construction and that selects a collocator (Mckeown \& Radev, 2000). To illustrate the presence of the base and that of the collocator, we can say that in the collocations give a lecture or deliver a lecture, for example, lecture is the base and this then selects for the collocators give and deliver, or another collocator, e.g., present (present a lecture). While in 
some cases a base can select for several collocators, as has been the case in the previous example, in case of more restrictive collocations the base only triggers one specific collocator, e.g., in the construction commit a suicide, suicide as the base can only select for the collocator commit. Considering the relation between the base and the collocators, collocations can be of different types, ranging from weak collocations to strong ones. Weak collocations have a high number of collocates (e.g., some color names (such as black in black man, black widow, black coffee, although in all cases black implies something different) or some adjectives, like great (e.g., when expressing feelings-great happiness, great joy or qualities-great pride, great wisdom, etc.) Weak collocations allow for the substitution of their constituent elements (e.g., in case of coffee we can have white coffee, iced coffee, canned coffee, decaff coffee, instant coffee, etc.).

By contrast, there are collocations that contain only a few number of collocates that are hardly interchangeable, so that we say rancid butter and addled eggs (in case the butter and the eggs go bad, both rancid and addled meaning 'stale' or 'rotten'), but 'addled butter' and 'rancid eggs' are quite unlikely collocations (Palmer, 1976). Between the spectrum of weak and strong collocations there is also a group of collocations called medium-strength collocations that allow for a limited number of specific collocates but disallow others. Such an examples is the collocator lecture that can select for deliver/give but not make (unless it is referred to the preparation of the presentation) or do (do a presentation is acceptable only when uttered in an informal context). According to Hill (2000, p. 64) and also Conzett (2000) it is medium-strength collocations that cause the most difficulty to students, and for this reason they should be given priority in class.

The semantic transparency of collocations can also vary considerably. A first group would constitute transparent collocations, where each constituent contributes to the meaning of the collocation as a whole; this is the case of words expressing relations of polysemy of homonymy, as in the examples to temper steel (temper meaning toughen) vs. to temper one's criticism (temper meaning making moderate) or to commit a crime (to carry out) vs. to commit oneself to do something (to obligate oneself) (Bartsch, 2004, p. 72). In case of transparent collocations, the verb may be delexicalized, in which case it is the noun that carries most of the meaning of the construction, consider for example tell a lie (lie), give a smile (smile), make a confession (confess). Nevertheless, even if the verb contributes little to the meaning of the construction as a whole, it defines its Aktionsart category, so that the construction give a smile expresses a voluntary action, and concentrates on the result rather than on the process of smiling; similarly, give a talk and tell a lie have slightly different meanings from talk and lie respectively, focusing on the end result of the activity, rather than on the activity itself. Finally, there are also collocations that do not have a semantically parallel full verb, such as for example take a picture, make a point. Collocations can be partly opaque, in which case one constituent carries a collocation-specific meaning, which differs from its meaning outside the construction, consider stiff drink (strong, intense), run for president (be a candidate), carry a grudge (feeling negatively about something) (Bartsch, 2004, p. 72). Finally, a collocation often expresses a meaning that exceeds the meaning of the constituents; the examples that Bartsch (p.73) gives are means on wheels (denoting a social welfare that involves carrying hot meals to the ones in need), to pop the question (proposing marriage), to put to the question (to interrogate by applying torture) or consenting adult (someone who has turned 18 and is legally responsible for his/her decisions), etc.

Collocations are often included in the same category with idioms, nevertheless in spite of the similarities they share they are also different. An important characteristics that differentiates collocations from idioms is their compositionality: idioms are non-compositional, semantically 
unanalyzable constructions, whereas collocations, though to some degree non - compositional and often lacking semantic transparency (Taylor, 2017) (e.g., running a business, does not have anything to do with running) are more analyzable semantically than idioms are.

\section{TEACHING COLLOCATIONS IN THE CLASSROOM. HOW?}

When planning to teach collocations, teachers have to bear in mind that language learners often have a hard time remembering and producing collocations. Several studies suggest that learners are in general quite slow at acquiring productive knowledge of L2 collocations (e.g., Durrant \& Schmitt, 2010; Hwang et al., 2017; Laufer \& Waldman, 2011; Li \& Schmitt, 2010; Nekrasova, 2009; Yamashita \& Jiang, 2010). Demir (2017, p. 75) notes that even by language learners who already have a good level of English the growth of the collocational competence stagnates as they are still dependent on the prefabricated routines acquired before. This is in line with Waller's observation (1993) who in his analysis of texts written by native and non-native speakers of English remarks that the EFL learners' deviant use of collocations is the most tangible marker of their non-nativeness. The reason for this might be as Kjellmer (1991) notes the fact that native speakers use large prefabricated sections, whereas language learners use bricks rather than string of words as their language material, having automated few collocations.

The reason why language learners have a hard time producing collocations can be multifold. One of them is a possible negative transfer from L1 (or L2 for that matter) so that for example while in Hungarian you say jó lenni valamiben (-ban, -ben meaning in), in English it is be good at something, in Hungarian you wash and not brush your teeth (fogat mosni), and you cook not make coffee (kávét fózni) etc. Boers, Lindstromberg \& Eyckmans (2014) note as an important reason for the slow uptake of verb-noun collocations by L2 learners the fact that especially in cases where the verb contributes little to the meaning of the construction as a whole (as is often the case with the hot verbs 'have' or 'tell') language learners tend to discard the verb and only look at the noun (noticing 'dream' in have a dream, 'lie' in tell a lie). Similarly, language learners often struggle with semantically similar verb constructions, such as 'make' and 'do', as in make a mess but do damage or 'say' and 'tell', as in tell the truth but say a prayer (Boers et al., 2014, p. 5). Webb and Kagimoto (2011) point out that semantically similar collocations are harder to learn than unrelated ones, some of them being also formally similar (as is 'take' and 'make', e.g., take a photo but make a drawing) (Boers et al., 2014, p. 5). Finally, an important reason for the insufficient and also inadequate use of collocations by language learners could be the fact that students are not aware of the existence of chunks in a language. As Wray (2002) points out language learners (especially adult ones) are used to seeing words separated by white spaces and as a consequence they tend to view and learn words separately instead of multiword chunks.

In order to remedy this situation, it is important that teachers draw language learners' attention to collocations and make them aware of the presence of multi-word chunks in the language. The importance of awareness in the language learning process has been noted in many studies (Fan, 2009; Lewis, 2000; Ramirez, 2012; Szabó, 2016) and also Lindstromberg and Boers (2008) who even propose a three-stage program for teaching multi-word chunks (collocations): 1.Helping learners notice chunks and raise their awareness of the importance of chunks in the language. 2. Helping students to memorize them (so that input becomes intake). 3. Helping students consolidate the knowledge they have acquired. 
Teaching collocations in the classroom can be quite challenging also because there are so many of them and also of different types. This paper supports Vasiljevic's (2014, p. 52) and also Hill's (2000, p. 64) idea that teachers should select and teach only those collocations that they consider important instead of trying to teach each and every collocation to the students. Teaching only a few collocations but repeating them with considerable frequency so that language learners can get used to them is an effective method, especially because as several studies point out (Macis, 2018; Webb et al., 2013) repetition can lead to incidental learning as well. Besides choosing what collocations to teach to students, teachers also need to decide on the teaching methods and strategies for teaching collocations. In what follows, the paper will present some activities and exercises that are considered to be useful for young adult learners, partly based on my idea, partly taking inspiration from linguists and experts dedicated to this field (Marks \& Wooder, 2007; McCarthy \& O’Dell, 1999, 2005, 2008; Shayna, 2013). When thinking of possible activities and tasks I have found the following factors to be of great relevance:

- Choosing activities and tasks that present collocations in their entirety, as a whole. This has been considered important especially because exercises on collocations in language books are often of the matching type (e.g., match the verb with the noun) or gap-filling (fill in the missing word). It is believed that while such exercises contribute to vocabulary enhancement they draw attention to parts of the construction, and not to the construction as a whole. In line with the idea of Boers et al. (2014, p. 19) who stress the importance of teaching collocations as intact wholes, it is believed that that language learners recall collocations better if they see them in their entirety.

- Choosing activities that students enjoy doing (types of group work that requires communication on a certain topic, doing surveys, listening exercises on a specific topic (e.g., Ted talks), activities where they can use computers or smart phones), role play and games (preferences communicated by my students). Activities that require creativity and problemsolving and that contain a bit of humor are generally loved by language learners.

- Choosing activities that do not exceed $30 \mathrm{~min}$ (except for the worksheet that might take longer) and can be used to complement the lesson in the classroom. This is because due to time and curriculum constraints teachers cannot dedicate entire classes to the teaching of collocations. The activities presented below don't require much preparation from the teacher which can be an important aspect when deciding on a certain activity to be done in the classroom.

- Choosing activities that can be done at various levels (elementary, pre-intermediate, intermediate and above) and for different purposes (of course, by applying the necessary modifications in the exercise). Choosing activities that integrate the language learning skills (speaking, reading, writing, and listening). As Sadiku (2015) points out an important advantage of an integrated skills approach is that it mimics real life situations, so that listening and speaking are often interrelated in real life and so are reading and writing.

\section{ACTIVITIES AND EXERCISES FOR TEACHING COLLOCATIONS}

\section{Exploiting a text}

Texts are full of collocations and as such they are a useful tool for teaching collocations. When preparing a text it is a good idea to highlight some of the collocations that the teacher thinks 
could be important for students (in case the text is already given in a language course book the teacher could write them on the whiteboard). In order to check how well language learners know a given construction, the teacher could ask the learner to give a synonym or a definition of certain pre-selected collocations (suitable for pre- intermediate level and above). Additionally, the teacher can also ask students to give the translation of the respective collocation; this might help students to see collocations as constructions and understand that they have a meaning of their own. Alternatively, the teacher can also give the definition of a specific collocation (or a synonym) and ask students to find that collocation in the text.

The teacher can also ask questions to provide a wider context for collocations. In the example below (taken from the transcript of a TED talk) the collocation get funding can be taught together with the expression to be underfunded. (Possible questions that the teacher can ask: What does it mean for a company to be underfunded? What can a company do to improve the situation? How does a company get funding? Can you give a synonym for intense funding? etc.). While in the example below the collocation get traction could be important at an upper intermediate level, at lower levels it is enough that students get the overall idea of what the sentence is about, without focusing on this specific collocation.

[..] If you're underfunded at first but you're gaining traction, especially in today's age, it's very, very easy to get intense funding

At lower levels, with texts that often describe every day activities, hobbies and interest, teachers can ask more personal questions (e.g., in case of go for a walk, Do you like going for a walk? How often do you go for a walk? With whom do you like going for a walk? etc. or provide a context for the collocation, e.g., Going for a walk is good because........... go for a walk if/when.....(making students complete the sentences with their own ideas).

As a follow-up activity the teacher can ask students to summarize the content of the text they have read in maximum three sentences by using a few selected collocations (not more than five). The activity can be done in various ways: either the teacher specifies which collocations to use, or the students select themselves. The students work in pairs and after they are finished they change partners and listen to their partner's version. At this task students should check if the selected collocations are present in the summary and also if they are used correctly (suitable for pre- intermediate level and above).

An alternative version of this activity can be to write the selected collocations on the whiteboard in a random order and ask students to put the collocations in the right order without looking at the text and then give the context of those specific collocations (suitable for all levels).

Another exercise is to make students work in small groups and give them a short story that is not finished. The task is to finish the story by using collocations that the teacher gives beforehand (here again it is important not to select too many collocations). The activity can be made even more interesting if each group has to finish the story in a different tone (happy ending, tragic ending, sad ending, open ending, funny ending, etc.) After they are finished, each group reads the ending out loud to the others.

\section{Listening exercises}

Listening exercises are useful for practicing collocations, as they reinforce the specific construction in the language learner's mind. As it has been pointed out before, repetition plays a key role in noticing and also memorizing collocations. Listening exercises can vary from songs to 
other types of recordings (stories, conversations, and TED talks) depending on the interest of that specific group and also their language level. At lower levels it is more suitable to listen to songs that include collocations (an activity could be to make them fill in the collocations that are previously taken out from the tape script). A funny song about collocations is the Collocation Grammar Song https:/www.youtube.com/watch?v=8HUeOzq_Q_E, a funny rewritten version of the Wannabe song by Spice Girls, a popular girl band. The song can also serve for a conversation about everyday activities, spare time activities and hobbies. In this case collocations can be taught together with frequency adverbials (always, never, sometimes, usually, often, every day, etc.).

Short films (especially the ones with a good storyline) can be used for practicing collocations as well. After watching the short film (silent films could work especially well) students are asked to write or rewrite the story in their own words by using some specific collocations the teacher gives beforehand. The activity can be done in pairs or as a group work and is suitable for all levels. Language learners (especially advance level students, but also ESP classes, like business students) often find TED talks interesting, as there are many topics covered they can relate to. While TED talks are usually quite long there are also shorter TED talks, not longer than 7-8 min that can be used to practice collocations. Depending on the level of the group, and as TED talks often involve specific vocabulary, the teachers might need to prepare beforehand a list of words that they consider useful for students, or even use the transcript, and highlight those collocations that student might not be familiar with. A listening exercise can be preceded and also followed by a speaking exercise (e.g., as an introductory exercise, students can be asked to think of or answer a few questions about the topic in small groups; a follow-up activity could be to give feedback on the presentation heard, focusing on some aspects of the talk. In both cases it is advisable that the teacher demonstrate the activity by writing on the whiteboard a few example sentences/formulae that students can use. Additionally, the teacher can tell students to focus on certain points that $\mathrm{s} / \mathrm{he}$ writes as phrases/collocations). Suitable for lower-intermediate levels and above.

\section{Speaking activities, games}

Many of the activities described above can be followed or preceded by speaking activities. They can vary from doing survey related to a specific topic (where students go around and ask each other some questions, e.g., when talking about sports, Can you ski? If yes, How often do you go skiing?) to discussing a specific topic in pairs or in small groups (e.g., Doing sports is necessary. Do you agree?). At lower levels, it is advisable that speaking exercises on collocations be done on a specific topic and be introduced by an introductory (e.g., brainstorming) activity, so that they language learners get acquainted with the necessary vocabulary.

Pictures and photos are often used as a teaching tool in the classroom and they are also applicable for practicing collocations. In one activity (similar to the Chinese Whispers Game) students work in groups of 5 or 6 . The teacher gives a picture story to one student in each group and asks him/her to pass on the message to the next person by whispering it in their ear. Students are only allowed to whisper and cannot show, mime or explain anything to each other. Funny picture stories (e.g., the one below) and also cartoon strips (Garfield, Calvin, and Hobbs comics, etc.) are ideal for this activity, as they can make students laugh. The activity is best suitable for intermediate level and above (as lower level students might not have the necessary 
vocabulary) and the teacher might decide to give several picture stories to the groups, in which case students take turns whispering to each other. At the end of this activity the last person to hear the story has to retell it to his/her peers, who will then see how well that story matches with what they have heard before (Figure 1).

At lower levels the teacher can hand out pictures containing collocations (e.g., on leisure activities) and have a discussion about them with the students, e.g., whether they like that activity and how often they do it (it can be done as a whole-class activity). In continuation, the teacher can also give students (working in pairs) pictures showing people talking to each other in different situations (similar to the one below). The task is to briefly describe each situation by using one or several collocations discussed before. As a follow-up activity, the students can be asked to write possible captions for each situation and then compare their answer to that of their peers (Figure 2).

Another speaking activity best done as pair work involves the use of mobile phones. Students show a photo (e.g., selecting from the photos on their phone) to their partner who then tries to guess what is happening in that picture by asking questions (e.g., I can see you are walking-are you on a trip here?, Are you celebrating something special?, etc.), the task being to find out as many details as possible about that specific photo. Students can find this activity interesting, the more so as it about them and their lives. This exercise, also suitable for lower levels, is best introduced by a brainstorming activity on phrases (and collocations) expressing habitual activities that the teacher writes on the whiteboard.

An interesting game that requires little preparation from the teacher and is suitable for the revision of collocations is the activity with post-it notes. The teacher writes a collocation on each

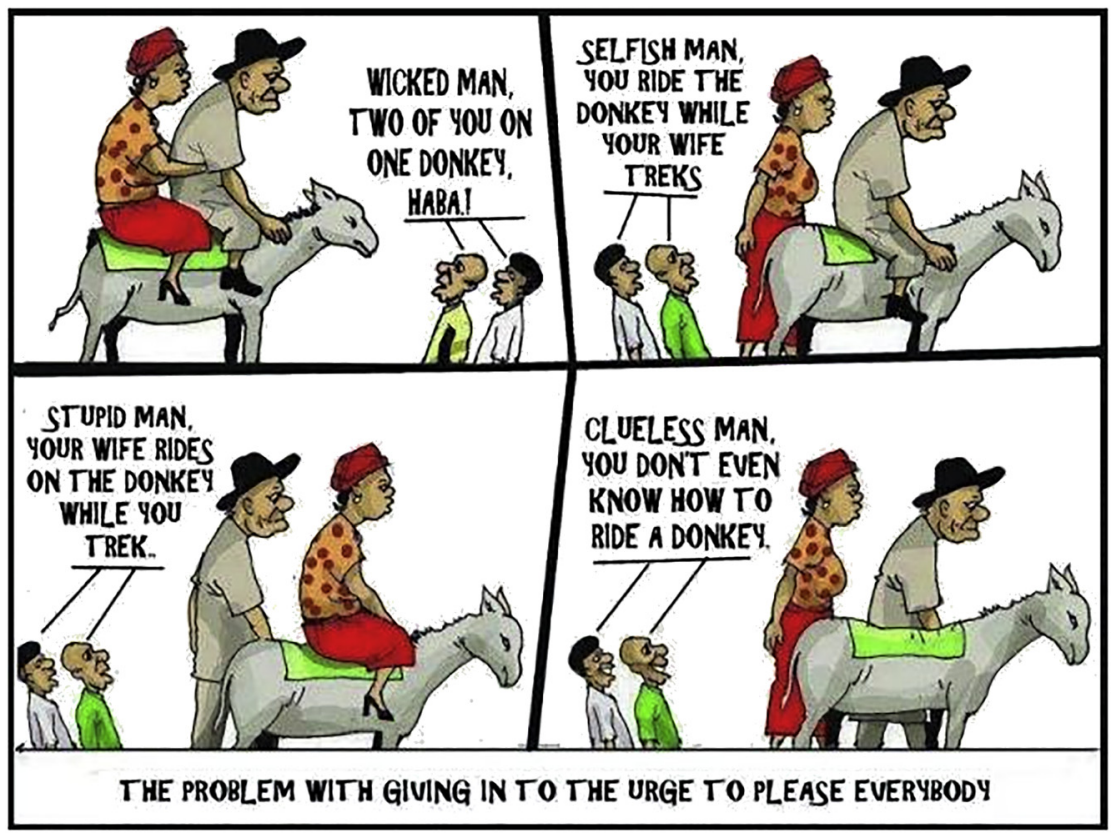

Figure 1. Picture story (Source: www.me.me) 


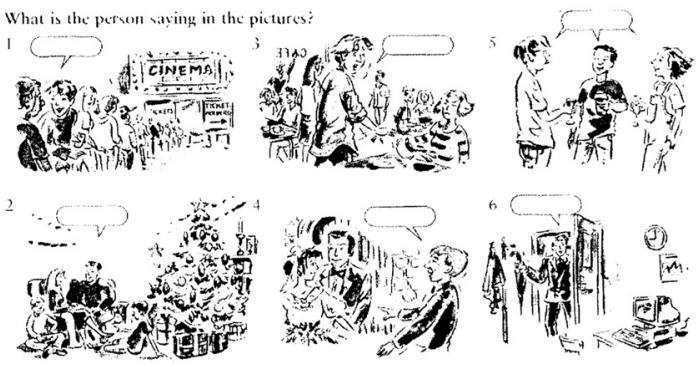

Figure 2. Describing social interactions. (Source: McCarthy \& O’Dell, 1999, p. 75)

post-it-note and places one on each student's back, in such a way that students are not able to see what is written on it. The students then go around and ask each other questions in order to find out information about that specific collocation. It is important that they should not ask each other directly what is written on their back, but only ask questions about it (e.g., Is it something that one can do regularly? Can you do this on your own? etc.)The partner can answer the question with one to three words only (e.g., yes, no, sometimes, not necessarily). This game works well with collocations related to a specific topic that the students have discussed in advance and is suitable for pre-intermediate level and above.

Flashcards can also facilitate the acquisition of collocations and can be used in many different ways. A useful website for creating flashcards is www.quizlet.com. After signing up on the website, the teacher can very easily create flashcards with collocations and their definitions (many of which are already implemented in the program's memory). The website is suitable for the practice of collocations at all levels and it even enables the use of several language pairs should the teacher choose to work with more than one language in class. An important advantage of this website is that it makes the learning process fun and enjoyable. There are several options available that allow language learners to memorize collocations, ranging from a sort of memory game (where one partner reads the definition of a specific collocation and his/ her colleague tries to guess the collocation) to other types of activities (e.g., of the matching type (matching the collocation with the definition), selecting the right answer, etc.) As students generally like using the internet and solving things, this can be an activity that they enjoy. Eventually, the teacher can also ask students to make some flashcard themselves (after they get used to using the website).

The use of smartphones or laptops will be necessary at the next activity called kahoot. At this activity the answer of each student counts, due to which it quickly gains popularity among language learners. After creating an account the teacher can use the platform for creating different types of activities, such as quiz questions on collocations, creating different answers for students to choose from (e.g., 2 or 3 false answers and 1 correct answer). Students, working either individually or in groups try to guess the right answer and by doing do they compete for the top score against their colleagues. Against a small monthly fee other options are also available that can help the teacher evaluate the progress of the students, such as adding polls to get feedback, getting reports on how well the students carry out a specific activity, etc. 
There are also other speaking activities that can be done on their own (and not as an introduction to a specific topic) and that can be fun for students. Such an activity is the game similar to the popular Activity board game, played worldwide. The teacher gives each group (consisting of 3-4 students) a pile of cards with collocations written on them. The piles are faced down and students take turns trying to guess the collocation written on the cards. The tasks vary from round to round (in one round the student presenting the collocation can only mime, in another one only draw, or only speak (without being allowed to say certain words related to that specific collocation). The game is more interesting if the groups play against each other but the activity can be done within one group as well.

Additionally, other vocabulary exercises, especially the ones that require problem solving (e.g., Hangman, or a quiz on a specific topic with the collocations highlighted) can also be effectively used for vocabulary practice.

\section{Worksheet on collocations}

Besides activities and games that facilitate learning in a playful way the teacher can also prepare a worksheet on collocations. This is especially useful if the aim is to revise collocations on a certain topic. Very useful in this sense are exercise books on collocations, such as Check your vocabulary for natural English collocations by Jon Marks and Alison Wooder (suitable for pre-intermediate level and above), English vocabulary in use (elementary level) and also English collocations in use (advanced level) by Michael McCarthy and Felicity O'Dell and English collocations in 10 minutes a day by Oliveira Shayna (suitable for higher levels).

Choosing a certain topic, such as for example food and eating habits the worksheet could include exercises that present collocations in their entirety, as a whole. It is often a good idea to introduce the topic with a short text containing collocations related to the topic. After students read the text (in this case suitable for intermediate level and above), the teacher can ask students to give a short definition of the highlighted collocations. The text below is an example of how the topic can be introduced to language learners.

My mother radically changed her eating habits a few years ago. In the past, she ate a lot of junk food (food that is not nutritious/healthy) and was overweight. Sometimes she would try to go on a diet (eat less food and healthier food), but it would never last. But now she understands how unhealthy processed foods are - they're full of food additives (chemicals added to food) that contribute to weight gain and heart problems.

Nowadays, she eats a balanced diet including a lot of nourishing meals (meals that are healthy and nutritious) that she prepares herself. She doesn't buy organic food because she thinks the prices are outrageous, but she stocks up on fresh produce (fresh fruits and vegetables) so that she can grab an apple or some veggies when she wants a quick snack (something small and fast to eat). She has also learned to eat in moderation and watch her portion sizes (how much food you take) [...]. (Source: Shayna, 2013, p. 15)

In order to make the activity enjoyable, a funny caption related to the topic can be inserted in the worksheet, similar to the one below (Figure 3). In addition, the teacher can also include another comic strip and ask students to write captions for it (better after the vocabulary practice when students have refreshed or mastered their vocabulary on the topic). Figure 4 is a good example for the topic food. 


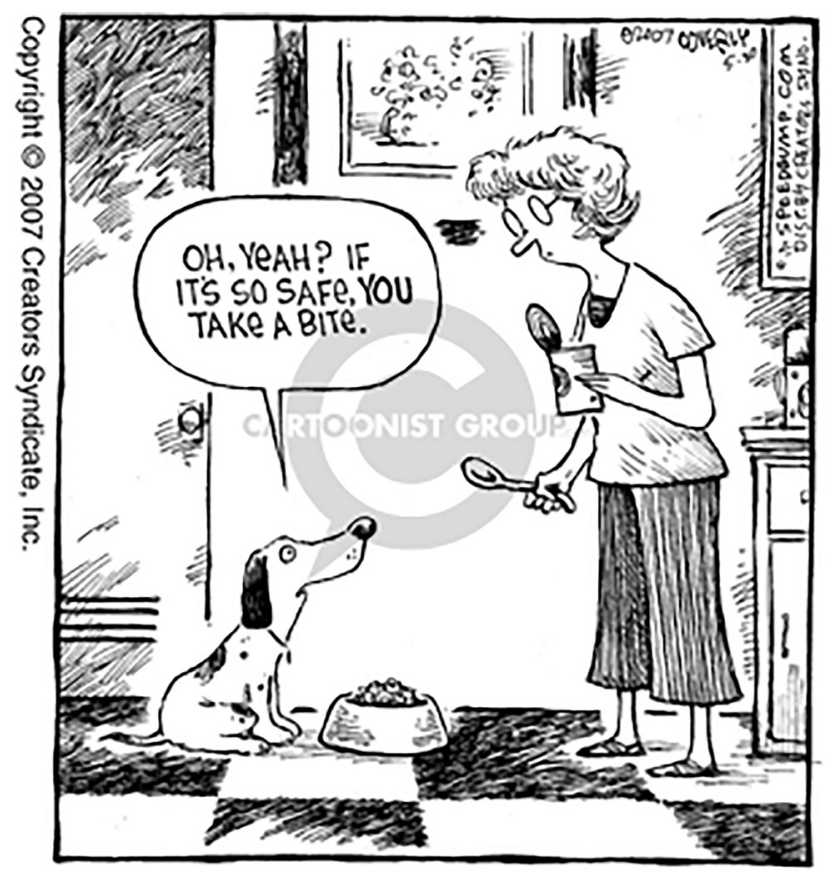

Figure 3. A funny caption related to the topic food. (Source: http://www.thecomicstrips.com/subject/TheFood+Safety-Comic-Strips-by-Speed+Bump.php)

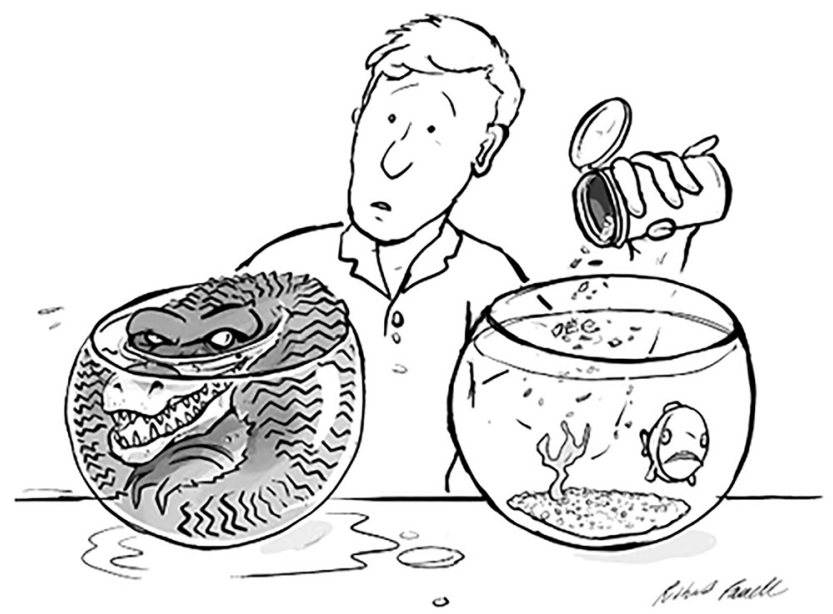

Figure 4. Write a caption for this image. (Source: http://www.davidsonian.com/caption-contest/) 
The following sentences are examples of exercises (meant for intermediate level and above) that can be used for practicing collocations in class:

1. Choose the correct word to complete the collocation:

The menu looks good. What are you going to order for your
a. Main course
b. main meal
c. main helping

2. What is the opposite of these expressions? Choose from these adjectives:

Stale sweet heavy mild still
a. a light meal
b. fresh bread
c. hot curry
d. sparkling mineral water
e. dry wine

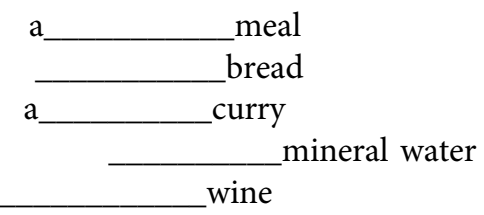

3. Complete these two-word expressions using the jumbled letters:

Bread and TRUBET

Salt and ERPPEP (Marks \& Wooder, 2007, p. 3)

4. Which is not a natural collocation?

a. A hearty/good/strong/healthy appetite

b. A three-course/evening/midday/night meal

c. A huge/hearty/compulsive/messy eater

d. A regional speciality/plate/dish

e. Speed/healthy/junk/fast food (Marks \& Wooder, 2007, p. 4)

5. Read these remarks by different people, then answer the questions.

Richard: I've got some cheese and milk. Is there a fridge here I could put them in?

Archie: I feel so hungry! I can't believe it!

Polly: I've been sick and my stomach is aching. Must be something I ate.

Ken: No matter how much I eat, I always want more.

Suzie: All these vegetables have been grown without any chemicals at all.

Nina: I always enjoy my food and look forward to it.

a. Who has organic food?

b. Who has an insatiable appetite?

c. Who has perishable food?

d. Who has a healthy appetite?

e. Who has food poisoning?

f. Who is dying of hunger? (McCarthy \& O’Dell, 2005, p. 51) 
6. Tick $(\checkmark)$ yes or no: Yes No

a. At home we have many kitchen facilities.

b. I often eat home-cooked food.

c. I don't mind doing the washing up.

d. I sometimes forget to clear the table after eating.

e. I never use paper towels in the kitchen.

As a follow-up to these exercises the teacher can ask students about their eating habits and also their preferences for food, using some of the collocations mentioned above.

\section{CONCLUSION}

Teaching collocations often comes with challenges, especially when adult learners are involved, who tend to learn words in isolation and also notice new words separately without their context. In order to make students memorize and use collocations correctly a very first step is to make them aware of the fact that some words go together and have a meaning on their own as a construction. A leading thought of this paper is that language learners need to repeatedly see and hear a certain collocation in its entirety, as a whole, in order to be able to recall it easily. The activities and exercises presented offer a plausible and hopefully useful way of teaching collocations to students.

Ethics: The study procedures were carried out in accordance with the Declaration of Helsinki.

Funding sources: No financial support was received for this study.

Authors' contribution: The author takes responsibility for the integrity of the data and the accuracy of the data analysis.

Conflict of interest: The author declares no conflict of interest.

\section{ACKNOWLEDGMENTS}

No additional acknowledgments.

\section{ABOUT THE AUTHOR}

Tünde Nagy is an assistant professor at Sapientia Hungarian University of Transylvania, Department of Human Sciences, Miercurea-Ciuc. Her research interests include but are not limited to foreign language teaching methodology, English as a lingua franca, comparative linguistics, morphology and the intersection between morphology and syntax, bi - and multilingualism, corpus linguistics, translation studies. 


\section{REFERENCES}

Bartsch, S. (2004). Structural and functional properties of collocations in English: A corpus study of lexical and pragmatic constraints on lexical co-occurrence: Gunter Narr Verlag.

Benson, M., Benson, E., \& Ilson, R. (1986). The BBI combinatory dictionary of English: A guide to word combinations. Amsterdam/Philadelphia: John Benjamins Publishing Co.

Boers, F., Lindstromberg, S., \& Eyckmans, J. (2014). Some explanations for the slow acquisition of L2 collocations. Vigo International Journal of Applied Linguistics, 11, 41-62.

Conzett, J. (2000). Integrating collocation into a reading and writing course. In M. Lewis (Ed.), Teaching collocation: Further developments in the lexical approach (pp. 70-87). Hove: Language Teaching Publications.

Demir C. (2017) Lexical collocations in English: A comparative study of native and non-native scholars of English. Journal of Language and Linguistic Studies, 13(1), 75-87.

Durrant, P., \& Schmitt, N. (2010). Adult learners' retention of collocations from exposure. Second Language Research, 26(2), 163-188.

Fan, M. (2009). An exploratory study of collocational use by ESL students - A task based approach. System, $37,110-123$.

Firth, J. (1957). Papers in linguistics, 1934-1951. London: Oxford University Press.

Goldberg, A. (1995). A Construction grammar approach to argument structure. Chicago: The University of Chicago Press.

Goldberg, A. (2006). Constructions at work. Oxford: Oxford University Press.

Hill, J. (2000). Revising priorities: From grammatical failure to collocational success. In M. Lewis (Ed.), Teaching collocation: Further developments in the lexical approach (pp. 47-70). Hove, England: Language Teaching Publications.

Hoey, M. (1991). Patterns of lexis in text. Oxford University Press.

Hwang, A., Wang, J., Józsa, K., Wang, P., Liao, H., \& Morgan, G. A. (2017). Cross cultural invariance and comparisons of Hungarian-, Chinese-, and English-speaking preschool children leading to the revised dimensions of mastery questionnaire (DMQ 18). Hungarian Educational Research Journal, 7(2), 4867. doi: 10.14413/HERJ/7/2/4.

Kjellmer, G. (1991). A mint of phrases. In K Aijmer, \& B Altenberg (Eds.), English corpus linguistics. Studies in honour of Jan Svartvik (pp. 111-127). London, New York: Longman.

Laufer, B., \& Waldman, T. (2011). Verb-noun collocations in second-language writing: A corpus analysis of learners' English. Language Learning: A Journal of Research in Language Studies, 61(2), 647-672.

Leech, G. (1974). Semantics: The study of meaning. Harmondsworth: Penguin Books.

Lewis, M. (2000). There is nothing as practical as a good theory. In M. Lewis (Ed.), Teaching collocation: Further developments in the lexical approach (pp.10-28). Hove, England: Language Teaching Publications.

Lindstromberg, S., \& Boers, F. (2008). Teaching chunks of language. Cambridge: Cambridge University Press.

Li, J., \& Schmitt, N. (2010).The development of collocations use in academic texts by advanced L2 learners: A multiple case study approach. In D. Wood (Ed.), Perspectives on formulaic language: Acquisition and communication (pp. 23-46). London/New York: Continuum.

Macis, M. (2018). Incidental learning of collocations from a semi-authentic novel: Three case studies. Reading in a Foreign Language, 30(1), 48-75. 
Marks, J. A., \& Wooder, A. (2007). Check your vocabulary for natural English collocations. London: A\&C Black Publishers.

McCarthy, M., \& O’Dell, F. (1999). English vocabulary in use, elementary: Cambridge University Press.

McCarthy, M., \& O'Dell, F. (2005). English Collocations in Use. Intermediate. How words work together for fluent and natural English. Cambridge University Press.

McCarthy, M., \& O’Dell, F. (2008). English collocations in use, advanced: Cambridge University Press.

Mckeown, K. R., \& Radev, D. R. (2000). Collocations. In R. Dale, H. Moisl, \& H. Somers (Eds.), A handbook of natural language processing (pp. 507-523). New York: Marcel Dekker.

Nekrasova, M. T. (2009). English L1 and L2 speakers' knowledge of lexical bundles. Language Learning, 59(3), 647-686.

Palmer, F. R. (1976). Semantics: A new outline. Cambridge: Cambridge University Press.

Ramirez, A. T. (2012). The lexical approach: Collocability, fluency and implications for teaching. Revista de lenguas para Fines Especificos, 18, 237-254.

Sadiku, L. M. (2015). The Importance of four skills reading, speaking, writing, listening in a lesson hour. European Journal of Language and Literature Studies, 1(1), 29-31.

Schmid, H. J. (2003). Collocations: Hard to pin down, but bloody useful. Zeitschrift für Anglistik und Amerikanistik, 51(3), 235-258.

Shayna, Oliveira (2013). 1000 English collocations in 10 minutes a day. Retrieved from https://vk.com/ doc2603620_443968436?hash=e26c890e53d982b059\&dl=ff1410487708ec0017.

Sinclair, J. (1991). Corpus, concordance, collocation. Oxford: Oxford University Press.

Stubbs, M. (2009).Technology and phraseology. With notes on the history of corpus Linguistics. In U Römer, R. Schulze (Eds.), Exploring the lexis-grammar interface. Studies in corpus linguistics: Vol. 35 (pp. 15-31).

Szabó F. (2016). The motivational force of employing literature in a foreign language classroom. Hungarian Educational Research Journal, 6(1), 61-70. doi: 10.14413/HERJ.2016.04.05.

Taylor, J. R. (2017). Lexical semantics. In B. Dancygier (Ed.), The Cambridge handbook of cognitive Linguistics (pp. 246-261). Cambridge: Cambridge University Press.

Vasiljevic, Z. (2014). Teaching collocations in a second language: Why, what and how?. Elta Journal, 2(2).

Vilkaité, L. (2016). Are non-adjacent collocations processed faster?. Journal of Experimental Psychology Learning Memory and Cognition, 42(10), 1632-1642. doi:10.1037/xlm0000259.

Waller, T. (1993). Characteristics of near-native proficiency in writing. In H. Ringbom (Ed.), Near-native proficiency in English (pp. 183-293). Finland: Abo Akademi.

Webb, S., \& Kagimoto, E. (2011). Learning collocations: Do the number of collocates, position of the node word, and synonymy affect learning?. Applied Linguistics, 32, 259-276.

Webb, S., Newton, J., \& Chang, A. (2013). Incidental learning of collocation. Language Learning, 63(1), 91-120.

Williams, G., \& Millon, C. (2012). Palmer, Firth and internet: Drawing together collocational threads.

Proceedings of Corpus Linguistics 2011 (pp. 1-34). Birmingham, United Kingdom.

Wray, A. (2002). Formulaic language and the lexicon. Cambridge: Cambridge University Press.

Yamashita, J., \& Jiang, N. (2010). L1 influence on the acquisition of L2 collocations: Japanese ESL users and EFL learners acquiring English collocations. TESOL Quarterly, 44(4), 647-668.

Open Access statement. This is an open-access article distributed under the terms of the Creative Commons Attribution-

NonCommercial 4.0 International License (https://creativecommons.org/licenses/by-nc/4.0/), which permits unrestricted use, distribution, and reproduction in any medium for non-commercial purposes, provided the original author and source are credited, a link to the CC License is provided, and changes - if any - are indicated. 